\title{
Wealth for toil
}

\author{
Budget cuts to Australia's national science agency may have long-term effects on the country's \\ commitment to radio-astronomy science.
}

It wasn't the most promising start. When newly elected Australian prime minister, Tony Abbott, announced his cabinet in September 2013, many were shocked to learn that the line-up excluded a minister for science - a post featured in every cabinet since 1931 . The science portfolio was to be absorbed into those of the ministers for industry and education, prompting thousands of Australian researchers to hold their collective breath. Abbott responded by suggesting the government be judged "by our performance, not by our titles". What's in a name, after all?

Now, it seems, the time for judgement has come, with the Australia federal budget released last month amid widespread concern for the future of the country's national science agency, the Commonwealth Scientific and Industrial Research Organisation (CSIRO). The organization will be obliged to do away with 420 jobs before June 2015, in addition to the 300 going this month and the estimated 440 cut within the past year.

Research in radio astronomy is expected to feel the heat of this change. The field is one of several key areas marked for "reduction or exit" by the organization. What this means exactly, remains to be seen. CSIRO has pledged support for the pre-construction phase of Australia's part in the international Square Kilometre Array (SKA) project, set to be one of the largest radio telescopes ever constructed (Nature Phys. 7, 739; 2011, and Nature Phys. 8, 505; 2012). But it is unclear how the project will fare if support from CSIRO is subsequently withdrawn. Eleven governments around the world are collaborating on the radio-telescope project, including the UK, which is chipping in 20 per cent of construction costs - a bold $£ 100$ million commitment. The rest of the funds remain to be raised.

The question-marks over funding for a project that boasts such international support and attention speaks to the broader impression that Australian science is a rudderless ship. The general consensus is that the nation's scientific pursuits suffer from inadequate planning and uncertain funding, on a federal scale. The budget does include AU\$150 million pledged for large infrastructure projects - such as the
SKA - through the National Collaborative Research Infrastructure Scheme (NCRIS). But this pledge has a one-year expiry date.

Also falling under the umbrella of NCRIS funding is the Australian Synchrotron - a case in point for poor long-term planning. The world-class facility was constructed with an initial investment of AU\$200 million and opened in 2007 amid much fanfare. But adequate ongoing funding for the facility was not forthcoming. So far, only nine beam lines have been built, despite the facility's capacity for 38. Australian Nobel laureate and astrophysicist Brian Schmidt has his own take on the matter: "It's as if Australia bought a \$200 million car and drives it only around the block, because it's too expensive to put it on the road."

Matthew Bailes, pro-vice-chancellor at Swinburne University of Technology, Melbourne, sees this as a general trend, commenting that state and federal governments are "often keen to fund the construction of iconic pieces of equipment but steadfastly refuse to provide running costs." Australia's key role in the SKA project should not suffer the same fate.

\section{Open for business?}

\section{Will government intervene if private-sector investment conflicts with national research interests?}

Industry is naturally a significant funder of research and development; its interests often leaning into surprisingly fundamental research rather than focusing exclusively on development. The once mighty Bell Labs ${ }^{1}$ was a famous example, but a recent resurgence of private-sector interest in essentially 'basic' research has been noted ${ }^{2}$, with companies such as Google and Microsoft at the fore. However, the responsibility for R\&D may not always sit easily in private hands,

particularly when the demands of society and shareholders compete.

Such is the situation evidenced by US pharmaceutical giant Pfizer's bid to take over the British-based company AstraZeneca. In the US, concerns have been raised that it is merely a strategy for tax avoidance ${ }^{3}$. In the UK, the issue strikes to the heart of its science base ${ }^{4}$, with Pfizer accused of wanting merely to asset-strip AstraZeneca. An open letter ${ }^{5}$ signed by scientists including astronomer and former Royal Society president Sir Martin Rees, and Rob Miller, director of the Rolls Royce University Technology Centre in Cambridge, UK, claimed that, "It is essential for the scientific future of the UK and its technological base that we have a pharmaceutical industry that is committed to work with UK universities and research scientists."

Last month, Pfizer and AstraZeneca bosses testified in front of two UK parliamentary select committees, for business and for science. But assurances, sought by the government, from Pfizer as to what level of $R \& D$ it would maintain in the UK after a merger have not hit the mark - rather they were dismissed by opposition leader Ed Miliband as "worthless".
Business secretary Vince Cable has raised the possibility of "legislative remedies" changes in law that might extend the rules of 'public interest' into the R\&D sector.

As Nature Physics goes to press, Pfizer has laid a "final" $£ 69$ billion offer on the table already dismissed by AstraZeneca's board. However, it remains to be seen whether the bid might tempt AstraZeneca's shareholders. If it does, the UK government must decide how far it is willing to intervene to protect national research interests that rest in private hands.

\footnotetext{
References

1. Nature Phys. 4, 665 (2008)

2. Drake, N. Nature 509, 18-19 (2014).

3. Krasny, R. \& Bartz, D. Reuters (14 May 2014); http://go.nature.com/1XZXe7

4. James, W. Reuters (15 May 2014); http://go.nature.com/2gTIjR

5. Knapton, S. The Telegraph (7 May 2014);

http://go.nature.com/AIAduP
} 